\title{
Coronal-Radicular Amputation or Hemisection? A Report Case in Lower Molar
}

\author{
Diana Araujo Espino', Vicente Esparza' ${ }^{2}$, Cesar Gaitan Fonseca ${ }^{1}$ \\ ${ }^{1}$ Area de Ciencias de la Salud, Universidad Autonoma de Zacatecas, Zacatecas, Mexico \\ ${ }^{2}$ Facultad de Medicina, Universidad Autonoma de San Luis Potosi, San Luis Potosi, Mexico \\ Email:fonseca_001@hotmail.com
}

Received 13 January 2016; accepted 24 May 2016; published 27 May 2016

Copyright (C) 2016 by authors and Scientific Research Publishing Inc.

This work is licensed under the Creative Commons Attribution International License (CC BY). http://creativecommons.org/licenses/by/4.0/

c) (i) Open Access

\begin{abstract}
The coronal-radicular amputation or radicular hemisection is defined as the sectioning fragments coronal-radicular of the lower molar with clinical damage followed endodontic treatment and prosthetics rehabilitation. This clinical treatment is viable in presence of the radicular decay or furca damage. This is a report case of radicular hemisection of lower molar with decay and bone loss that compromise distal root. The objective was elimination of distal root and conserved mesial root with endodontic and prosthetics treatment.
\end{abstract}

\section{Keywords}

\section{Radicular Hemisection, Lower Molar Inferior, Distal Root}

\section{Introduction}

The hemisection is a clinical procedure to refer the sectioning of a mandibular molar in two fragments, followed by the removal of diseased root and its coronal portion [1] [2]. Then retained root is treated endodontically for its subsequent prosthetic rehabilitation [3]. This procedure preserves partial tooth structure and reduces the resorption of alveolar bone [4].

Indications for the root hemisection include:

1) Solution of prosthetics problem: a) loss of the structure of a fixed prosthesis support; b) decay of root lesion at level of the furca.

2) Solution for periodontal disease, including lesions at level of the furca.

3) Solutions for endodontic problem: a) failure of previous canal treatment; b) root resorption; c) complication 
of endodontic treatment or root perforation.

4) Solution for vertical root fracture with multiradicular teeth [5].

The success of the hemisection of molar treatment depends on the following factors: the selection of the case, accurate diagnostic and periodontal status (level of alveolar bone support), establishing optimal occlusal forces with minimum trauma, performing satisfactory endodontic procedures, placing a fixed prosthesis and establishing an optimal oral hygiene environment [6].

The aim of this paper is to describe and show an option of clinical treatment of hemisection in a patient with decay and bone loss in mandibular molar.

\section{Case Report}

Female 44 years old, enters the dental clinic CLICAM of University of Zacatecas, Mexico, referred by the Zacatecas Health Center for endodontic treatment. In the medical examination, the patient not referred history of systemic disease. The clinical examination reveals plaque, extensive decay in OD. 46 limited to the mesial portion of the clinical crown. The pain sensitivity test was negative. Radiograph evaluation presents a minimal bone loss and radiolucent area involving the root furcation and distal root, without mesial tooth affectation (Figure 1(a)). The diagnosis was pulp necrosis of OD. 46. Two treatment options explained to the patient, one of them is the hemisection of the distal root of the molar, and their subsequent rehabilitation and as a last alternative, intends total extraction and placement of a fixed prosthesis. The patient chose the treatment of hemisection. As first step was the removal of decay with a ball bur \#2, the mesial canal treatment of the OD. 46 was conducted, vestibular and lingual canals was filled with gutta-percha [Hygienic, Coltene, Germany], cementing with seala$\operatorname{pex}^{\mathrm{TM}}$ [Sealapex, Sybronendo, USA] (Figure 1(b)) and temporary sealed with cavit ${ }^{\mathrm{TM}}$ [3M ESPE, Spain].
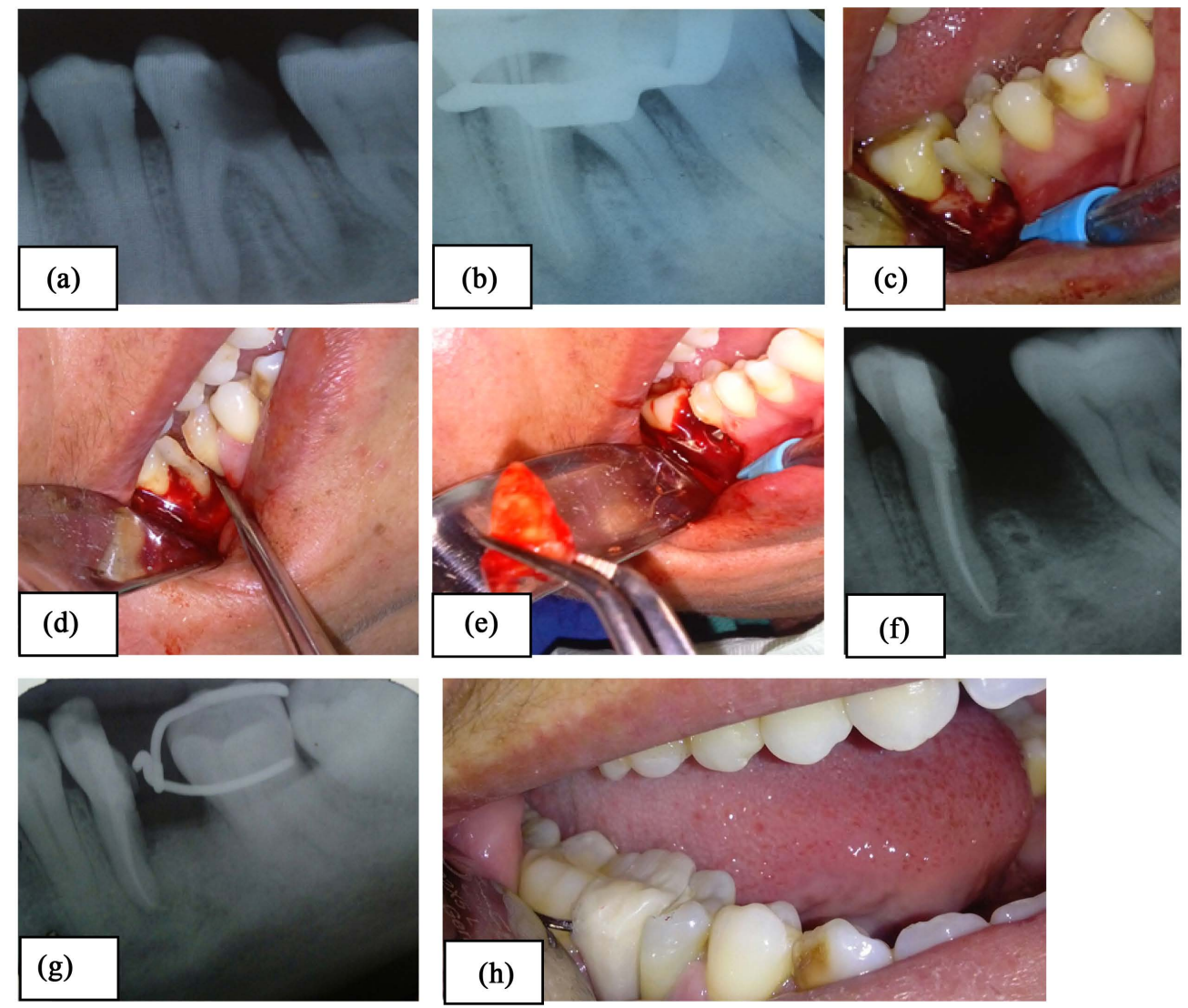

Figure 1. Steps of hemisection radicular. (a) Periapical X-ray initial with decay in furca and loss of dental structure in distal wall; (b) Endodontic procedure in mesial root; (c) Hemisection radicular; (d) Division of roots with elevators; (e) Distal root extracted; (f) Final X-ray with root canal finished; (g) Control radiograph 3 months; (h) Final restoration. 
After one week was finished the hemisection of the tooth number 46, with the technique described follow, the flap should provide adequate visualization and instrumentation access and minimize surgical trauma (Figure 1(c)). The section cut was performed with a high-speed fissure bur and the extraction of the distal root were made, being careful traumatize or damaging the roots and adjacent bone (Figure 1(d) and Figure 1(e)).

If necessary, bone surgery is performed to regularized the alveolar bone and discover the margins of the root structure for seal the final restoration. Before placed the flap, we take an x-ray that verify the continuity of the cut section (Figure 1(f)), making sure not to leave a dentinal step that prevents an adequate adaptation of the soft tissue and generate difficulties for adequate fit of the restoration. After 3 months a final restoration was placed and control radiograph were made (Figure 1(g) \& Figure 1(h)) without clinical and radiographic symptoms.

\section{Discussion}

The radicular hemisection or coronal radicular amputation is an alternative clinical in multirradicular teeth with periodontal and decay damage. These procedures have contraindications: roots are fused, inability to perform an endodontic-prosthetic treatment and non acceptation patient [6]. The present report case describes a clinical management of radicular hemisection in OD. 46 with periodontal damage in distal root, endodontic treatment and prosthetic rehabilitation were placed. Actually in dentristy exists immense advances and clinical options for patients to conserve teeth how periodontal, endodontic and operatory treatments. The lower molars are the more frequently extracted because a high incidence of decay and periodontal disease that involved furca or roots that impossibility endodontic and prosthetic treatments. In this topic the radicular hemisection or coronal-radicular amputation plays an important role for conservate these teeth [7].

Saad et al. (2009) reported a hemisection in molar with affectation distal, it was pillar in prosthetic restoration of units three, it was affected with extends cavity in middle third. Endodontic treatment in mesial canals and hemisection of the distal root were made. Immediately provisional restoration was placed and three months later a definitely fixed prosthesis was place and follow-up 1 year with a satisfactory result. Therefore, it suggests that the radicular hemisection was an appropriate treatment in this particular clinical condition, where damage was limited in root distal [8]. Pai et al. reported a similar case in 2014 and concluded that coronal radicular amputation or hemisection can be an alternative as another treatment modality by conservative lower molar with furca damage [9].

Although the successes of a hemisection tooth depends factors how: periodontal condition, endodontic treatment, prosthetic rehabilitation, patient cooperation, bone quality and support preserved root preserved. Park (2009) reported a case with mobility in two molars, a hemisection mesial root and distal root the first and second molar were made respectively. The final restoration was carried using a temporary filled for one month and three months later a finally restoration was placed [10]. In hemisection procedures two factors are very important: first endodontic treatment and second the final restoration, for it is necessary given an enough time for healing and remodeling of periodontal tissues. Scientific evidences showed that the maturation of periodontal tissues occurs after three months of the surgery [11]. In radicular hemisection, hybrid prosthesis is used; include an endodontic treatment and prosthetic rehabilitation [12]. In this case report we used a hybrid prosthetics with a prosthetic and endodontic treatment in mesial root and distal root hemisection.

Anita and Rao (2015) reported other option of radicular hemisection, in clinical cases that present a vertical fracture in a single root with healthy periodontium, the other root give a provides good retention and support for definitive prosthesis [13].

\section{Conclusion}

Finally the coronal-radicular amputation or hemisection is a viable clinical treatment to preserve a multiradicular tooth with periodontal, trauma and decay implications in furca. It is indispensable good clinical criteria based on diagnosis, prognosis for case selection, endodontic-prosthetic treatments for clinical success and clinical control.

\section{References}

[1] Varma, K.M., Chittem, J., Satish, R.K., Kumar, M.S.R. and Sajjan, G.S. (2014) A Novel Approach for Restoration of Hemisectioned Mandibular Second Molar with Modified Tunnel Restoration: A Case Report. Journal of Clinical and Diagnostic Research, 8, 7-9. 
[2] Kost, W.J. and Stakiw, J.E. (1991) Root Amputation and Hemisection. Journal of the Canadian Dental Association, 57, 42-45.

[3] Rapoport, R.H. and Deep, P. (2016) Traumatic Hemisection and Restoration of a Maxillary First Premolar: A Case Report. General Dentistry, 51, 340-342.

[4] He, Y., Hasan, I., Keiling, L., Chen, J., Pan, Q., Huang, Y. and Bourauel, C. (2016) Combined Implant-Residual Tooth Supported Prosthesis after Tooth hemisection: A Finite Element Analysis. Annals of Anatomy, pii: S0940-9602(16) 30002-4. http://dx.doi.org/10.1016/j.aanat.2016.01.002

[5] Taintor, J. and Ingle, J. (1998) Cirugía Endodóntica. Endodoncia. 5ta Edition.

[6] Andrei, O.C., Dăguci, C. and Maliţa, M.A. (2010) Case Report: The Influence of Coronoradicular Amputation on the Shape of the Subsequent Prosthetic Restoration. Romanian Journal of Morphology and Embriology, 51, 779-781.

[7] Radke, U., Kubde, R. and Paldiwal, A. (2012) Hemisection: A Window of Hope for Freezing Tooth. Case Reports in Dentistry, 2012, Article ID: 390874. http://dx.doi.org/10.1155/2012/390874

[8] Saad, M.N., Moreno, J. and Crawford, C. (2009) Hemisection as an Alternative Treatment for Decayed Multirooted Terminal Abutment: A Case Report. Journal of the Canadian Dental Association, 75, 387-390.

[9] Pai, A.R.V., Babu, V.M. and Kundabala, M. (2016) The Role of Hemisection in the Prosthetic Management of a Distal Extension Ridge-A Case Report. Dental Update, 41, 514-516.

[10] Park, J.-B. (2009) Hemisection of Teeth with Questionable Prognosis. Report of a Case with Seven-Year Results. Journal of the International Academy of Periodontology, 11, 214-219.

[11] Dowling, E.A., Maze, G.I. and Kaldahl, W.B. (1994) Postsurgical Timing of Restorative Therapy: A Review. Journal of Prosthodontics, 3, 172-177. http://dx.doi.org/10.1111/j.1532-849X.1994.tb00149.x

[12] Yadav, P., Tahir, M., Kumar, M.V. and Rao, H. (2013) Prosthetic Rehabilitation of a Hemisected Maxillary Molar: A Rare Entity. Journal of Indian Prosthodontic Society, 13, 373-377.

[13] Anitha, S. and Rao, D.S. (2015) Hemisection: A Treatment Option for an Endodontically Treated Molar with Vertical Root Fracture. The Journal of Contemporary Dental Practice, 16, 163-165. http://dx.doi.org/10.5005/jp-journals-10024-1654 